\title{
ESPELHO DE ÁGUA: A CIDADE DE COIMBRA VISTA A PARTIR DO RIO MONDEGO
}

\section{WATER MIRROR: COIMBRA CITY SEEN TROUGHT MONDEGO RIVER}

\author{
Alves, Bruno Franco \\ (Instituto de Ciências Sociais Aplicadas, Universidade Federal de Juiz de Fora-GV / Doutorando em \\ Sociologia: Cidades e Culturas Urbanas, Centro de Estudos Sociais e Faculdade de Economia da \\ Universidade de Coimbra)
}

\begin{abstract}
RESUMO
A urbanização das cidades passa pelos usos sociais que são feitos dos seus rios. Refletir sobre os rios urbanos apresenta-se então como uma possibilidade de interpretar sociologicamente o processo de configuração dos espaços das cidades, a construção da sua identidade e a projeção de sua imagem e, sob essa perspectiva, torna possível também discutir os projetos de cidade que se buscam construir. O presente estudo parte da seguinte questão: qual a importância do Rio Mondego na constituição das paisagens urbanas da cidade de Coimbra? Para compreensão da paisagem urbana de Coimbra a partir do Mondego propõe-se uma pesquisa de cariz qualitativo, com privilégio aos componentes sociais que compõem a paisagem desse rio. Valendo-se do método regressivo-progressivo proposto por Lefebvre se buscará pensar a cidade e sua história a partir da relação com o rio para refletir sobre os processos sociais que configuraram o contexto urbano atual de Coimbra.
\end{abstract}

Palavras chave: rios urbanos, requalificação, Coimbra, Mondego

Bloco temático: La ciudad Poscrisis.

\section{ABSTRACT}

The urbanization of cities passes through the social uses that are made of their rivers. Reflecting on urban rivers presents itself as a possibility to interpret sociologically the process of city space configuration, the construction of its identity and the projection of its image and, from this perspective, it also makes it possible to discuss city projects that they seek to build. The present study is based on the following question: what is the importance of the Mondego River in the constitution of the urban landscapes of the city of Coimbra? To understand the urban landscape of Coimbra from Mondego it is proposed a qualitative research, with privilege to the social components that make up the landscape of this river. Using the regressive-progressive method proposed by Lefebvre, it is sought to think of the city and its history from the relationship with its river to reflect on the social processes that shaped the current urban context of Coimbra.

Keywords: urban rivers, requalification, Coimbra, Mondego

Topic: Poscrisis city. 


\section{Introdução}

"As cidades testemunham com uma força expressiva rara o que foram as etapas anteriores das civilizações humanas." (Lacaze, 1999, p. 1). Essa sentença de efeito com a qual Jean-Paul Lacaze inicia sua A cidade e o urbanismo coaduna-se à própria questão de partida deste ensaio e reflete as inquietações acadêmicas da pesquisa de doutoramento do autor, ainda em fase inicial: qual a importância dos rios nesses testemunhos civilizacionais contidos na leitura das cidades? Como os usos desses rios revelam as cidades, sua história, morfologia, seus modos de vida e paisagens?

O local onde se encontram as cidades no espaço geográfico e a sua configuração muito tem a ver com a relação que essas cidades estabelecem com as águas. Transporte de pessoas e mercadorias, proximidade às áreas agricultáveis, condições favoráveis à defesa e à construção de portos. (Lacaze, 1999, p. 16; Pelletier \& Delfante, 2000, p. 30). Essa constatação é válida também quando se trata das cidades portuguesas. As suas duas cidades mais populosas, Lisboa e Porto, são banhadas por rios de grande extensão e volume de água. Em outras cidades portuguesas, os rios também assumem uma feição de importância que se revela, inclusive, na toponímia dos lugares: Arcos de Valdevez, Ferreira do Zêzere, Miranda do Douro, Paredes de Coura, Ponte de Lima, Ribeira de Pena, Sever do Vouga, Vila Nova de Paiva, Vila Velha de Ródão, por exemplo, são sedes de concelho em Portugal que evocam em sua toponímia os cursos de água que os percorrem (Caldas, 2006, p. 154).

A importância dos rios no imaginário social português também se revela nas manifestações culturais. O Rio Mondego, por atravessar a cidade de Coimbra, berço da primeira universidade portuguesa, tornou-se assim uma referência constante na música, na poesia e na literatura nacionais, sendo citado nos poemas de Luiz de Camões, Eugénio de Castro e Miguel Torga.

Não obstante a importância assumida pelos rios na constituição da vida urbana, a relação entre os rios e suas cidades nem sempre é harmoniosa, de forma que o processo de ligação entre as cidades e seus rios é marcado por rupturas e reconciliações, ora fazendo-se cidade "apesar" dos rios e ora "integrando" o rio, mas sempre a lidar com a sua presença. Se em um primeiro momento das cidades os rios exercem uma função geográfica central que leva à atração e sedentarização das pessoas em suas proximidades, com a Revolução Industrial opera-se uma cisão entre os rios e as cidades.

A promessa capitalista de crescimento econômico ininterrupto aliada ao antropocentrismo da filosofia moderna que concebe as pessoas como externas e superiores à natureza criaram as justificativas ideológicas para que a natureza pudesse ser indiscriminadamente "dominada" e "subjugada" pelos seres humanos para a satisfação das suas necessidades. (Latour, 1994).

Em relação aos rios urbanos, pode-se dizer que essa perspectiva contribui para a sua condição de invisibilidade e degradação. A construção de portos fluviais, de fábricas e armazéns às margens dos rios para se valer das facilidades de transporte e do aproveitamento da água como recurso industrial acabaram por obstruir o contato, inclusive visual, entre a cidade e sua população com os rios. Nesse sentido, inicia-se um processo de funcionalização do espaço urbano que passa a contar com áreas portuário-industriais, de acessibilidade limitada e funções exclusivamente econômicas, e, de outro lado, a cidade da vida cotidiana, com sua área residencial, comercial e de lazer. (Coy, 2013).

$\mathrm{Na}$ cidade pós-industrial, esse processo de relação rio-cidade tende a transformar-se novamente. Como assinala Carlos Fortuna, a flexibilização pós-fordista, conjugada com o processo duplo de desindustrialização e reindustrialização teve como efeito a criação de espaços vazios no interior das cidades. (Fortuna, 2002, p. 127). Dentre esses espaços, podem ser citados os portos, as fábricas, armazéns e edificados que foram instalados nas margens dos rios em muitas cidades durante os séculos XVIII a XIX e que deixaram de exercer a sua função originária, mas, devido à expansão territorial das cidades, se encontram em plena área urbana. (Coy, 2013). 
Essas grandes áreas nas margens dos rios, outrora decadentes e desvalorizadas, ficaram disponíveis para outros usos e sofreram um intenso processo de valorização a partir de investimentos tanto do poder público como da iniciativa privada na requalificação desses espaços dotando-os de novas funcionalidades, convertendo-se em locais de atração de pessoas, de investimentos, de pressão imobiliária e de especulação.

\section{Objetivos}

A pesquisa tem por objetivo geral analisar o processo de ocupação das margens do rio Mondego e os usos do seu leito na cidade de Coimbra a partir o século XX para explicar como foi construída essa relação cidade-rio e também para contextualizar questões urbanas de caráter mais geral como o planejamento público, as formas de sociabilidades na cidade contemporânea e as distintas possibilidades do ser humano se relacionar com a natureza.

Ao supracitado objetivo geral somam-se quatro objetivos específicos: i) conhecer a forma de ocupação, os usos e funções sociais das margens urbanas e do leito do rio Mondego em Coimbra; ii) identificar as alterações dessas paisagens ao longo do tempo, especialmente para entender a sua relação entre os usos sociais que eram e são feitos do rio; iii) observar o cotidiano dos rios, as pessoas e o objetos que se relacionam com ele, e quais os tipos de relação estabelecem; iv) verificar a historicidade presente na paisagem fluvial urbana e, partindo dela, buscar compreender aquilo que a cidade foi e aquilo que discursivamente constrói sobre seu futuro.

\section{Métodos}

Ao escrever sobre o desafio sociológico de compreender a produção do espaço Lefebvre afirma que esse mister está em "descrever o resultado atual, procurar sua explicação e determinar o conjunto do processo que desembocou nesse resultado." (Lefebvre, 1986, p. 170). Para tanto, propõe um método simples a que denomina regressivo-progressivo e que é composto de três momentos de pesquisa (Lefebvre, 1986, p. 173, 1991, p. 65):

a) Momento descritivo: nessa fase da pesquisa se realiza a observação no local da pesquisa. Os diversos elementos encontrados em campo são identificados e precisamente descritos com o emprego de técnicas como entrevistas, inquéritos por questionários e estatísticas;

b) Momento analítico-regressivo: trata-se da etapa em que a realidade social descrita na fase anterior será analisada. Remete à ideia já aqui referida de complexidade vertical do espaço, sendo necessária, portanto, a tarefa de regredir historicamente no tempo para datar com precisão as espacialidades e temporalidades que coexistem no tempo presente;

c) Histórico-genético: após regredir no tempo para datar as relações socioespaciais cabe o retorno ao tempo presente para então elucidá-lo e compreendê-lo. A complexidade vertical é lida dentro de um contexto mais amplo da gênese daquelas formações e estruturas em relação a um conjunto de fatores que com elas interagem.

Considera-se que a partir do emprego de técnicas variadas de coleta de dados no terreno, como a realização de entrevistas walking-along com citadinos comuns, a aplicação de questionários, a visita às margens do rio para identificação e registro de usuários, usos e equipamentos urbanos, levantamento de estatísticas e legislação pública relacionada ao rio poderão fornecer os elementos para materialização do momento descritivo. O momento analítico-regressivo será realizado com base nos registros históricos e o momento histórico-genético a partir da análise e reflexão a cerca de todos os dados levantados. 


\section{A relação da cidade com as águas: as funções urbanas dos rios}

Em sua Arquitetura Sociológica, Frederico de Holanda afirma que a paisagem natural e qualquer espaço construído são arquitetura. Partindo desse pressuposto, desenvolve oito aspectos que permitem caracterizar o desempenho espacial identificando a maneira como eles afetam as pessoas: aspectos funcionais, aspectos bioclimáticos, aspectos econômicos, aspectos sociológicos, aspectos topoceptivos, aspectos afetivos, aspectos simbólicos e aspectos estéticos. (Holanda, 2007, p. 117).

Tomando por referência esses aspectos é possível identificar e agrupar as principais funções urbanas desempenhadas pelos rios e suas margens. (Mello, 2011).

O aspecto funcional tem a ver com as exigências práticas da vida cotidiana. Pensado a partir do rio, este aspecto evidencia contornos utilitários como o uso das águas para o abastecimento humano, o saneamento básico, a pesca e coleta de espécies vegetais e animais, a agropecuária, a demarcação territorial, o lançamento dos esgotos residenciais e empresariais, a circulação e o transporte de pessoas e mercadorias, a segurança das cidades, a geração de energia, extração de minérios e materiais de construção.

Os aspectos bioclimáticos relacionam-se com as "condições adequadas de iluminação, acústica, temperatura, umidade, velocidade do vento e qualidade do ar." (Holanda, 2007, p. 117). Os rios e suas margens são usados também como fatores de conforto ambiental, vez que a presença da água contribui para humedecer o ar e amenizar a temperatura nas imediações, além de serem locais em que a ventilação é privilegiada pelo canal formado pelo eixo do rio. (Mello, 2011, p. 157).

Os aspectos econômicos tratam dos custos de implementação, manutenção e uso dos lugares e sua compatibilidade com o poder aquisitivo das pessoas implicadas. (Holanda, 2007, p. 117). Em sua relação com a cidade, os rios podem servir como elemento de desvalorização, quando estes são desprezados pelo desenvolvimento da malha, mas pode também se tornarem vetores de valorização econômica e social, principalmente com as intervenções urbanas de requalificação das frentes de água das cidades.

Os aspectos sociológicos implicam nas maneiras desejáveis de indivíduos e grupos sociais se localizarem nos lugares e nele se moverem, na obtenção de visibilidade do Outro e nas condições desejadas para encontros e esquivanças. (Holanda, 2007, p. 117). Os rios e suas frentes de água atraem expressivo número de pessoas, seja para contemplação da paisagem, seja pelo conforto climático gerado, seja em função de rituais religiosos, da prática de atividades desportivas, de lazer ou simplesmente para circulação.

Sobre os aspectos topoceptivos, Holanda analisa se o lugar é legível visualmente, se ele tem uma identidade e boas condições para a orientabilidade. (Holanda, 2007, p. 118). Os rios são elementos importantes para orientação dos indivíduos na cidade. Seguir até o rio, o bairro do outro lado do rio, o comércio à beira rio, ladear o rio até o final da avenida, enfim, o rio é referência de orientação geográfica para os transeuntes, nativos ou turistas, nas mais diversas cidades.

Ademais, a identidade de um lugar se constrói a partir de uma soma de características e peculiaridades que permitem que ele seja único ou mesmo que se identifique com outros lugares a partir de características distinguíveis que os tornem semelhantes.

Em A imagem da cidade, um dos conceitos trabalhados por Kevin Lynch é o da legibilidade, entendida como a "facilidade como a qual as partes podem ser reconhecidas e organizadas numa estrutura coerente." (Lynch, 1990, p. 13). Já a imagibilidade da cidade é constituída a partir de objetos físicos que são capazes de evocar imagens fortes em quem os observa. Refere-se à forma, cor ou disposição que formam de imagens mentais do ambiente fortemente identificadas, poderosamente estruturadas e altamente úteis (Lynch, 1990, p. 20). O conceito de imaginabilidade liga-se assim ao de legibilidade, uma vez que as "imagens fortes" possibilitam uma visão mais nítida e estruturada da cidade.

Os rios inegavelmente conferem legibilidade às suas cidades e contribuem na construção da identidade que compõe a sua imagem. Longe de ser uma decorrência natural dos seus objetos, a imagem da cidade varia 
conforme o observador, pois é sempre o resultado da interação de alguém com alguma coisa, a representação que um sujeito tem de um objeto. (Lynch, 1990, p. 16; Peixoto, 2000, p. 104). A este relativismo imagético das cidades soma-se o fato de que no processo de produção das imagens a cidade ora é objeto, ora é sujeito. Isso porque a imagem das cidades é tanto aquela que a pessoa realiza, como aquela que é difundida pela própria cidade a partir da sua autorrepresentação no marketing urbano no intuito de constituir e propagar uma determinada identidade da cidade e posicioná-la na competição entre lugares. (Peixoto, 2000, p. 104).

Sobre os aspectos afetivos é preciso verificar como o rio afeta o estado emocional das pessoas. (Holanda, 2007, p. 118). A forma como as pessoas reagem ou sentem/experenciam esses locais também demonstra que os locais possuem uma personalidade afetiva. As pessoas podem estar mais à vontade à beira rio, serem mais informais, agirem com mais simplicidade e intimidade. Mas o mesmo rio pode despertar sensações de grandeza, solenidade e soberba, por exemplo, de hóspedes de um hotel de luxo ou habitantes de um edifício simplesmente por estarem em alguma área valorizada à beira rio.

Os aspectos simbólicos remetem para elementos como a valores, ideias e história. (Holanda, 2007, p. 118). Os rios são lugares da cidade repletos de simbologia. De início, podemos destacar que a água é um elemento natural presente nos rituais das mais diversas religiões e que os rios, em muitos lugares, são utilizados para esses rituais e possui estatuto de sagrado. Também podem servir para contar a história de lugares, representar grandes acontecimentos, conquistas, episódios da história local, ideais de vida e valores de um povo.

Se alguma(s) dessas funções podem levar ao afastamento entre a cidade e o rio, o aspecto estético é, ao contrário, o principal responsável por fazer resistir o desejo de ligação com as águas. Sobre esse aspecto, Holanda (2007, p. 118) sugere que se inquira sobre a beleza do local, sobre as suas qualidades, sobre a sua capacidade de estimulação autônoma dos sentidos para além de questões práticas.

A existência de cursos de água na cidade como rios, riachos e cachoeiras, ou de outros elementos como lagos e lagoas, sempre foram considerados um ativo valorizador da paisagem urbana. Os atributos estéticos das frentes de rio tem sido um dos motivadores da valorização dos espaços à beira-rio, especialmente daqueles que sofreram intervenções de requalificação, conectando os aspectos estéticos aos econômicos o que pode ser visto na consolidação do interesse comercial e residencial dessas cidades, com a instalação de restaurantes, bares, clubes, hotéis e alojamentos locais e novos edifícios de moradia, na presença constante de turistas nessas áreas e na pressão e expulsão daquelas pessoas que vivam e ocupavam essas áreas antes das citadas intervenções.

As diversas funções e usos dos rios variam conforme as cidades e as características dos próprios rios de forma que essa relação modeladora atua em duplo sentido: a cidade moldando o rio e o rio moldando a cidade. Como pontua João Castro Caldas (2006, p. 154), as marcas da água estão impressas nos relevos, nas paisagens, na composição biológica dos ecossistemas, nas formas de utilização dos territórios, na toponímia e identidade dos lugares, na inspiração de artistas. De outro lado, as marcas das cidades também estão impregnadas sobre o rio e podem ser vistas no formato assumido por seu leito, na altura de sua calha, na cor e velocidade de suas águas, no seu ecossistema, nas construções que sobre o seu curso se lançam ou que ao seu redor prosperam, na sua capacidade de atrair pessoas e de ser contemplado.

Nas cidades, os rios são, ao mesmo tempo, elementos que compõem o sistema natural, com dinâmicas hídrica, geológica e biológicas próprias, mas também são elementos sociespaciais que fazem a cidade. Pensar nos rios urbanos é, portanto, evocar as suas águas e sua antropização, seus diversos usos ao longo da história, para refletir sobre aquilo que são e aquilo que as cidades são, enfim, é descortinar a paisagem urbana a partir das águas. 


\section{A relação entre o Rio Mondego e a cidade de Coimbra: resultados esperados}

Os rios são elementos que estão umbilicalmente ligados aos processos sociais que as cidades vivenciam tanto na estruturação do território urbano como na conformação de suas paisagens. Como locais que comumente geram a atração das pessoas, os rios urbanos e as suas margens nas cidades estão impregnados de práticas sociais, culturais e econômicas que podem revelar processos históricos de relação entre a cidade e seus cursos d'água e a forma como essas paisagens foram e são (re)produzidas e (re)significadas.

O Rio Mondego é o mais extenso rio situado integralmente em território português, com um percurso total de $258 \mathrm{~km}$ desde a sua nascente, no Parque Nacional da Serra da Estrela, até a sua chegada ao oceano Atlântico, em Figueira da Foz. (Lobo, Peixoto, Mota, Duxbury, \& Caiado, 2016). Por esse longo caminho, o Rio Mondego vai assumindo diferente utilidades e funções, conformando também diferentes paisagens.

Em seu percurso urbano na cidade de Coimbra, o Mondego encontra-se confinado por margens que foram artificialmente construídas com o intuito de controlar as suas águas e proteger a cidade das recorrentes inundações.

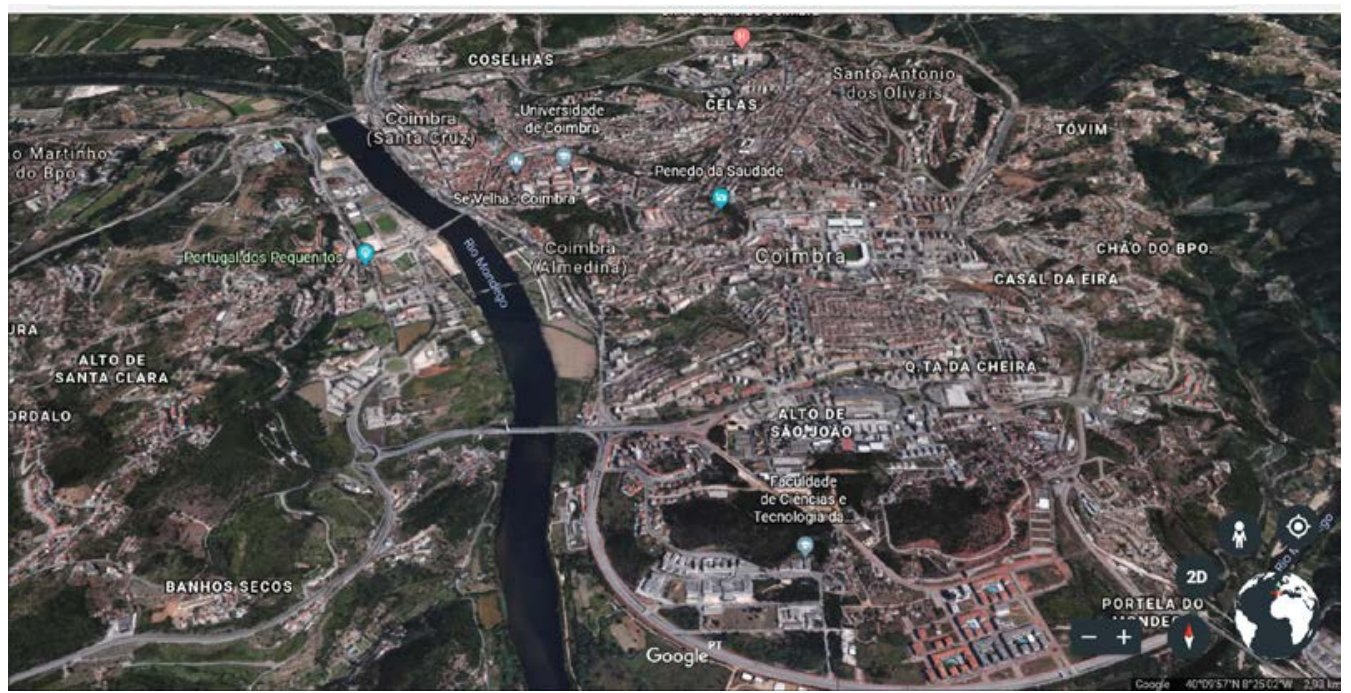

Fig. 01 Vista aérea do rio Mondego e Coimbra Fonte: Google Earth

O desenvolvimento urbano da cidade de Coimbra sempre esteve marcado pela presença do Mondego. Pelas suas condições de navegabilidade, tanto o Mondego, como a ria, onde provavelmente desaguava entre os séculos VIII a XI, influenciaram a localização e a primeira fase do desenvolvimento da cidade. Nesse sentido, Coimbra foi crescendo condicionada pelo seu rio, ocupando as colinas às suas margens, os espaços do antigo leito, as vertentes e a planície aluvial que o cercava. (F. Rebelo, 2012). 


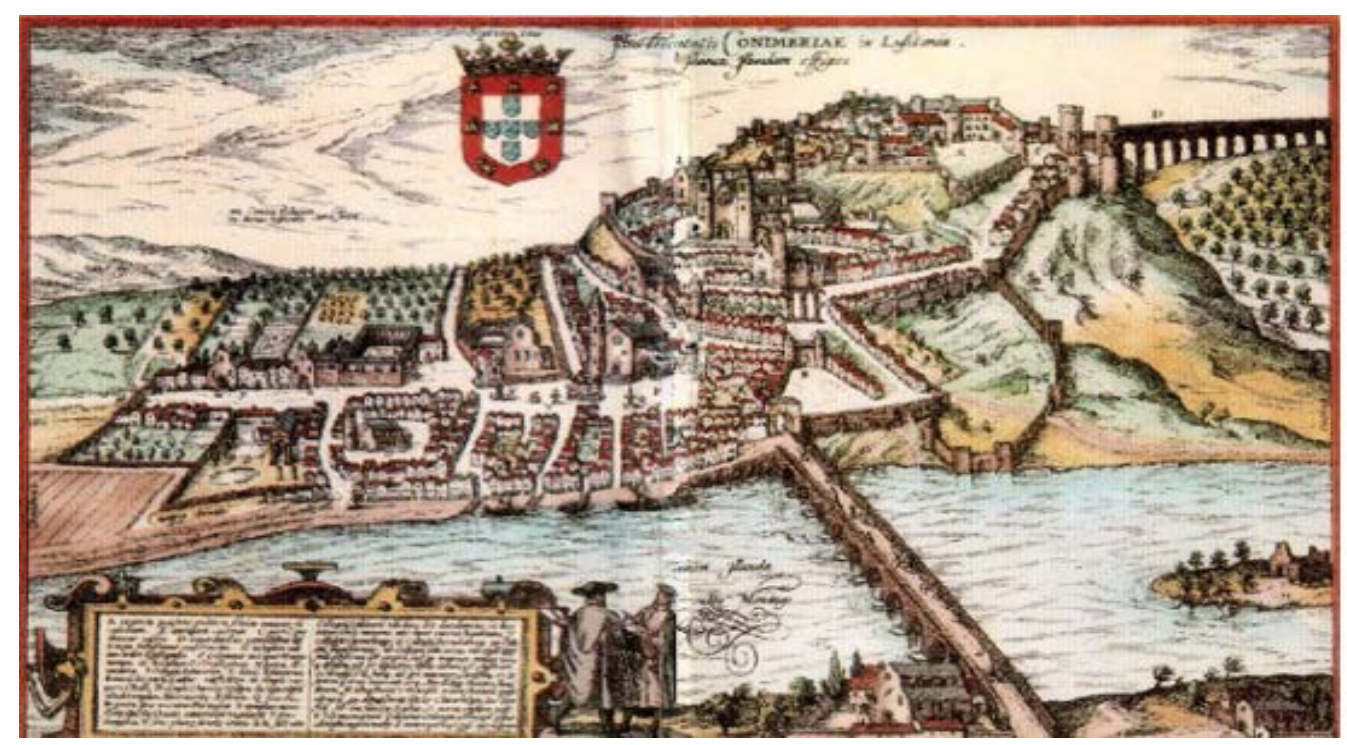

Fig. 02 Coimbra no século XV Fonte: (Almeida, 2006)

As cheias no rio Mondego se tornaram frequentes e capazes de provocar extensas inundações especialmente a partir do século XIV, das quais se destacam as dos anos de 1331, 1788, 1821, 1842, 1852, 1860, 1872, 1900, 1915, 1962, 1969 e 1979, 2001 e, mesmo sem consequências graves, a de 2012 -13 e a de 2016. (Lobo et al., 2016). Os efeitos maléficos das inundações foram objeto de preocupação, discussões e de intervenções desde os fins do século XVIII. Elisa Almeida cita o estudo e projeto de obras e soluções do Padre Estevão Cabral, intitulado "Sobre os damnos do Mondego no Campo de Coimbra e seu remédio", e o artigo "Sobre o encantamento do Rio Mondego", ambos de 1790, como exemplos de que os problemas de Coimbra e do baixo Mondego começaram a ser encarados de forma global ainda nessa época. (Almeida, 2006).

Para além das cheias, o assoreamento contínuo do leito do Mondego alterou também um dos usos que dele se fazia: a navegação. As barcas serranas constituíram meio de transporte privilegiado entre o interior e o litoral, ligando Coimbra ao Oceano Atlântico, mas o assoreamento progressivo do leito aumentou a dificuldade da navegação no Mondego levando ao desaparecimento do tráfego fluvial na década de 1950. (Lobo et al., 2016).

Até meados do século XX o Rio Mondego oferecia a Coimbra praias fluviais onde as pessoas se animavam e refrescavam no verão. Essa beira rio era frequentada também pelas "lavadeiras do Mondego" que durante todo o ano exerciam ali seu ofício.

Embora desde os fins do século XVIII se tenha realizados projetos e intervenções mais pontuais com o intuito de minimizar os efeitos das cheias e do assoreamento do rio, é nos anos sessenta do século XX que se elabora um "Plano geral do aproveitamento hidráulico da bacia do Rio Mondego", executado a partir dos anos setenta. (Almeida, 2006; Lobo et al., 2016). O referido plano considerou as diversas utilizações que se faz da água na bacia hidrográfica do Rio, nomeadamente, a agricultura, a indústria, a produção de energia elétrica e o abastecimento público de água (Lobo et al., 2016) e alterou significativamente o Mondego e a cidade de Coimbra.

Para além das mudanças de ordem climática e do maior controle sobre as cheias, uma das consequências da execução desse plano é a transformação substantiva no aspecto visual e nos usos do Rio Mondego. Em todo o seu perímetro urbano na cidade de Coimbra o rio passou a correr em um canal artificial. Com a construção de um dique urbano, a Ponte do Açude, em 1981, o Mondego passou a se apresentar à cidade como um suntuoso espelho d'água integrando-se à sua paisagem urbana. 
Controlados os efeitos do assoreamento e das inundações, a cidade se pês a recuperar sítios históricos e a instalar novos equipamentos urbanos em suas margens, estimulando o seu uso para a prática de esportes, lazer e recreio da população e também dinamizando a urbanização de sua margem esquerda.

A infraestrutura mantida junto às margens do Mondego, especialmente o Parque Manuel Braga e o Parque Verde do Mondego, que desde 2006 liga as suas duas margens por meio da ponte pedonal Pedro e Inês (imagem 1), configura uma das paisagens do rio em sua porção urbana que, todavia, coexistem com outras paisagens bem diferentes, como aquela que entre a Ponte de Santa Clara e a Ponte Açude, na Avenida Aeminium (imagem 2).

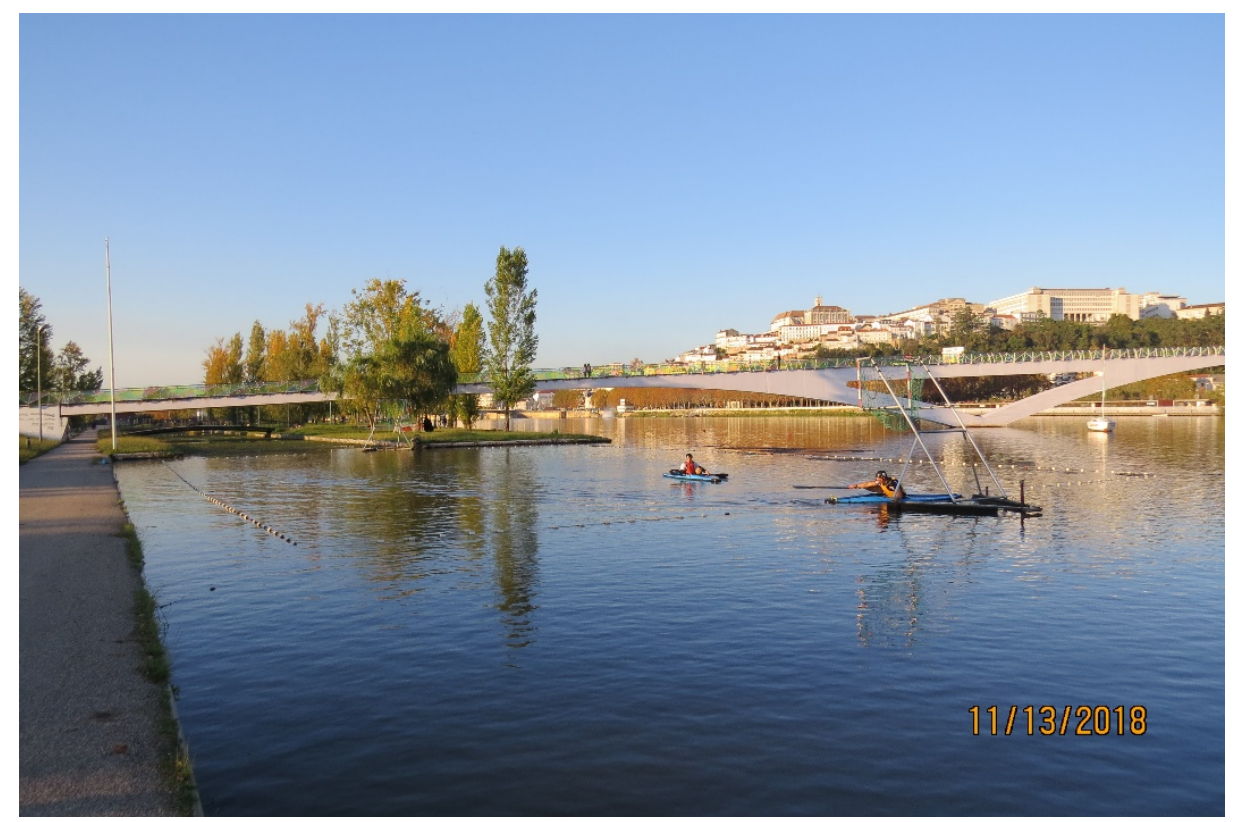

Fig. 03. Ponte Pedro e Inês Fonte: O autor

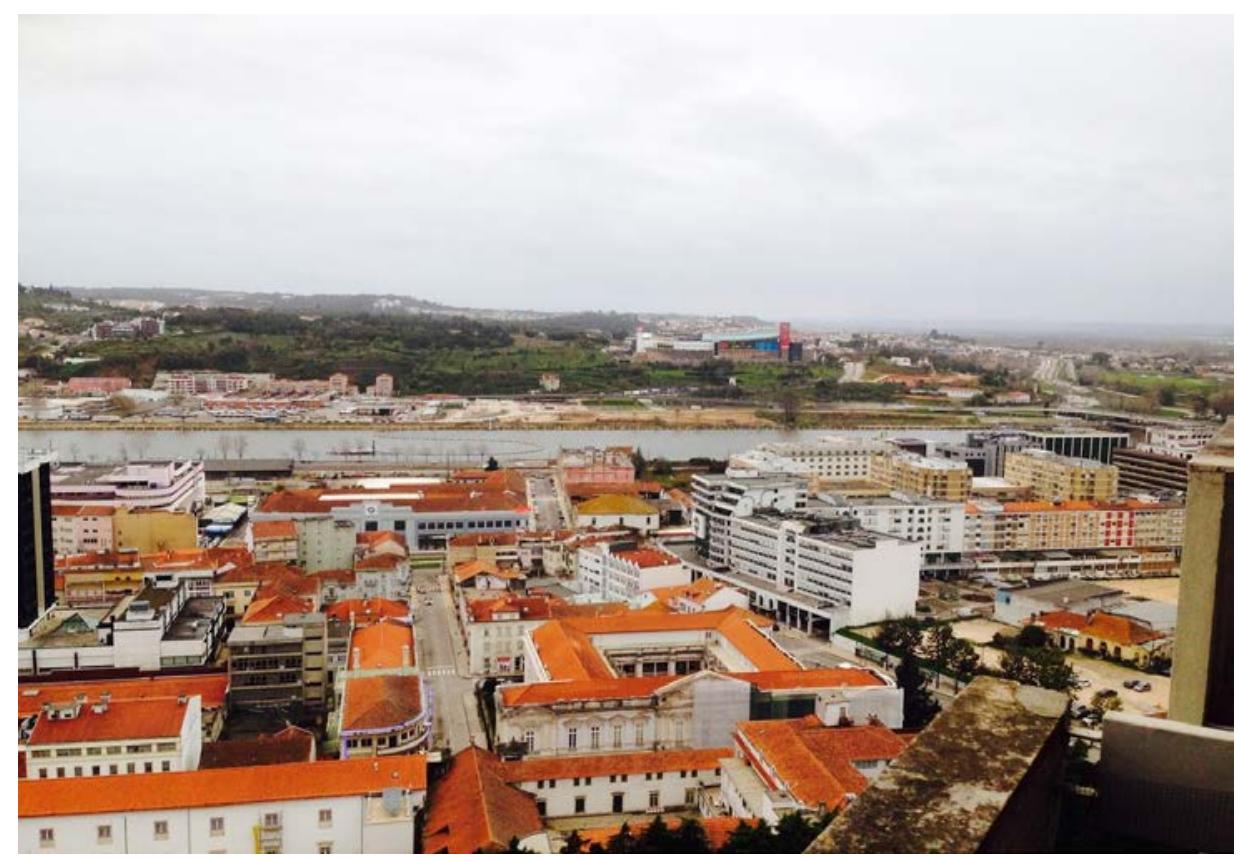

Fig. 04. Vista de Coimbra e do Rio Mondego Fonte: O autor 
A história de Coimbra e do Rio Mondego são indissociáveis, sendo que tomando como perspectiva os usos sociais que foram e são feitos do leito do rio e de suas margens ao longo da história espera-se como resultado da pesquisa a constatação de que o rio começa a assumir a partir dos fins da segunda metade do século XX uma nova centralidade na cidade que não é mais relacionada à sociabilidade cotidiana, mas que liga-se ao lazer das classes médias urbanas e à sua função cênica, já que é peça fundamental na imagem que a cidade projeta em seu marketing urbano. Mesmo assim, espera-se que no terreno sejam encontrados sujeitos, objetos e práticas que ainda carregam consigo o registro da historicidade passada dessa relação rio-cidade.

\section{Considerações finais}

Nas cidades, os rios são ao mesmo tempo elementos que compõem o sistema natural, com dinâmicas hídrica, geológica e biológicas próprias, mas também são verdadeiros lugares que fazem a cidade e integram o espaço urbano. Pensar nos rios urbanos nos permitirá discutir a forma como a cidade contemporânea vem sendo historicamente construída e, especificamente, na tensão atual entre a cidade vivida, a representação dessa mesma cidade e os fundamentos sociais, culturais e económicos que lhes orientam.

Milton Santos define paisagem como um conjunto de objetos distribuídos sobre um dado território, apreendidos em sua continuidade visível e que ganham vida e significação por meio dos processos sociais. (Santos, 1985 apud Gorski, 2008, p. 30). Possui uma dinâmica própria que ao mesmo tempo é condicionada pela sua natureza originária que determina em algum grau a sua forma e a sua relação com a história social que origina as suas transformações. (Peyret, 2016, p. 50). Para entender a paisagem de Coimbra e do Mondego é imperativo assim entender os processos sociais que lhes subjazem.

O Mondego e suas margens vistos como um palimpsesto (Canclini, 1998) contribui para que se possa compreender essa paisagem urbana que foi sendo constituída ao longo dos tempos por acréscimos, substituições, sobreposições e eliminação de elementos, uma escrita sobre a outra e formando um conjunto de objetos com idades diferentes, herança de momentos diferentes, que revelam, cada um, parcelas importantes do passado e também do futuro da cidade. (Santos, 1988).

O Mondego é muito rios em um rio. É o rio cantado nos fados e nas poesias, é o rio das lavadeiras, o rio das praias fluviais, dos pescadores, das fábricas de porcelana, da linha de comboio, dos barcos a remo, do Parque Verde, e também é o rio que quer ser dos turistas, que quer ancorar a projeção de Coimbra na competição internacional das cidades. Por meio do método regressivo-progressivo proposto por Lefebvre acredita-se que a pesquisa será capaz de identificar os diversos marcadores dos tempos históricos que convivem no espaço, conhecendo como este espaço foi e continua a ser produzido em seu cotidiano e revelando os fundamentos que orientam, condicionam e, ao mesmo tempo, são por eles condicionados.

\section{BIBLIOGRAFIA}

ALMEIDA, E. M. D. (2006). Coimbra e o Rio Mondego. Em J. REBELO (Coord.), Evolução do espaço físico de Coimbra (93-106). Coimbra: Câmara Municipal de Coimbra.

CALDAS, J. C. (2006). Água e desenvolvimento. Os territórios de Alqueva. Em M. L. FONSECA (Coord.), Desenvolvimento e território: espaços rurais pós-agricolas e novos lugares de turismo e lazer: homenagem à Professora Doutora Carminda Cavaco (pp. 153-169). Lisboa: Centro de Estudos Geográficos da Universidade de Lisboa.

CANCLINI, N. G. (1998). Las cuatro ciudades de México. Em N. G. CANCLINI (Ed.), Cultura y comunicación en la ciudad de México I. Modernidad y multiculturalidad: la ciudad de México a fin de siglo (pp. 19-39). México: Universidad Autonoma Metropolitana Iztapalapa.

COY, M. (2013). A interação rio-cidade e a revitalização urbana: experiências europeias e perspectivas para a 
América Latina. Confins (São Paulo), 18, 72-95.

FERREIRA, V. M. et al. (1997). Lisboa, a metrópole e o rio : centralidade e requalificação das frentes de água. Lisboa: Bizâncio.

FORTUNA, C. (2002). Culturas urbanas e espaços públicos: sobre as cidades e a emergência de um novo paradigma sociológico. Revista Crítica de Ciências Sociais (Coimbra), 63, 123-148.

GORSKI, M. C. B. (2008). Rios e cidades: ruptura e reconciliação. Universidade Presbiteriana Mackenzie. Obtido de http://tede.mackenzie.br/jspui/handle/tede/2632 (Consulta: 17/04/2018).

HOLANDA, F. (2007). Arquitetura sociológica. Revista Brasileira de Estudos Urbanos e Regionais (São Paulo), 9(1), 115-129.

KOHLSDORF, M. E. (1996). A apreensão da forma da cidade. Brasília: Editora da Universidade de Brasília.

LACAZE, J. P. (1999). A cidade e o urbanismo. Lisboa: Instituto Piaget.

LATOUR, B. (1994). Jamais fomos modernos: ensaio de antropologia simétrica. Rio de Janeiro: Editora 34.

LEFEBVRE, H. (1986). Perspectivas da sociologia rural. Em J. de S. MARTINS (Org.), Introdução crítica à sociologia rural, 2. ${ }^{a}$ ed. (163-177). São Paulo: Hucitec.

LEFEBVRE, H. (1991). The production of space. Oxford, UK \& Cambridge, USA: Blackwell.

LOBO, R. et al. (2016). Mondego: o surdo murmúrio do rio. Em J. P. CARDIELOS, PEIXOTO, Paulo (Org.), A água como património: experiências de requalificação das cidades com água e das paisagens fluviais (95112). Coimbra: Imprensa da Universidade de Coimbra.

LYNCH, K. (1990). A imagem da cidade. Lisboa: Edições 70.

MELLO, S. S. de. (2011). Na beira do rio tem uma cidade: urbanidade e valorização dos corpos d'água. Universidade de Brasília. Obtido de http://repositorio.unb.br/handle/10482/1608 (Consulta: 17/04/2018)

PEIXOTO, P. (2000). Gestão estratégica das imagens das cidades: análise de mensagens promocionais e de estratégias de marketing urbano. Revista Crítica de Ciências Sociais (Coimbra), 56, 99-122. - (2016). Os usos sociais dos rios. Em P. Peixoto, J. P. Cardielos (Org.), A água como património: experiências de requalificação das cidades com água e das paisagens fluviais (57-70). Coimbra: Imprensa da Universidade de Coimbra.

PELLETIER, J., DELFANTE, C. (2000). Cidades e urbanismo no mundo. Lisboa: Instituto Piaget.

PEYRET, P. (2016). Vias de água, paisagens: a noção de patrimônio fluvial. Em P. Peixoto, J. P. Cardielos (Org.), A água como património: experiências de requalificação das cidades com água e das paisagens fluviais (47-56). Coimbra: Imprensa da Universidade de Coimbra.

REBELO, F. (2012). Rio Mondego e Coimbra: uma longa e ambivalente ligação. Revista Portuguesa de História (Coimbra), 43, 149-158.

SANTOS, M. (1988). Metamorfoses do espaço habitado: fundamentos teóricos e metodológicos da geografia. São Paulo: Hucitec. 